Article

\title{
Strawberry FaNAC2 Enhances Tolerance to Abiotic Stress by Regulating Proline Metabolism
}

\author{
Jiahui Liang ${ }^{1}$, Jing Zheng ${ }^{1}$, Ze Wu ${ }^{2}$ (I) and Hongqing Wang ${ }^{1, *}$ \\ 1 Department of Fruit Science, College of Horticulture, China Agricultural University, Beijing 100193, China; \\ bs20173170791@cau.edu.cn (J.L.); sy20193172524@cau.edu.cn (J.Z.) \\ 2 Key Laboratory of Landscaping Agriculture, Ministry of Agriculture and Rural Affairs, College of \\ Horticulture, Nanjing Agricultural University, Nanjing 210095, China; wuze@njau.edu.cn \\ * Correspondence: wanghq@cau.edu.cn; Tel.: +86-13683018901
}

Received: 23 September 2020; Accepted: 21 October 2020; Published: 23 October 2020

\begin{abstract}
The quality and yields of strawberry plants are seriously affected by abiotic stress every year. NAC (NAM, ATAF, CUC) transcription factors are plant-specific, having various functions in plant development and response to stress. In our study, FaNAC2 from strawberry (Fragaria $\times$ ananassa, cultivar "Benihoppe") was isolated and found to be a member of the ATAF sub-family, belonging to the NAC family of transcription factors. FaNAC2 was strongly expressed in the shoot apical meristem and older leaves of strawberries, and was induced by cold, high salinity, and drought stress. To investigate how FaNAC2 functions in plant responses to abiotic stress, transgenic Nicotiana benthamiana plants ectopically overexpressing $F a N A C 2$ were generated. The transgenic plants grew better under salt and cold stress, and, during simulated drought treatment, these transgenic lines not only grew better, but also showed higher seed germination rates than wild-type plants. Gene expression analysis revealed that key genes in proline biosynthesis pathways were up-regulated in FaNAC2 overexpression lines, while its catabolic pathway genes were down-regulated and proline was accumulated more with the overexpression of $F a N A C 2$ after stress treatments. Furthermore, the gene expression of abscisic acid biosynthesis was also promoted. Our results demonstrate that FaNAC2 plays an important positive role in response to different abiotic stresses and may be further utilized to improve the stress tolerance of strawberry plants.
\end{abstract}

Keywords: strawberry; ATAF; FaNAC2; abiotic stress

\section{Introduction}

Agricultural crops grow in a constantly changing environment and are often subjected to abiotic stresses such as drought, heat, cold, and high salinity. These stresses are associated with increased accumulation of certain deleterious chemicals like reactive oxygen species (ROS), which affect the stability of cell membranes and the structure of proteins, finally leading to reduced crop yield and even death [1,2]. To adapt to environmental stress and complete their life cycle, plants have evolved a complex mechanism that tightly regulates gene expression through precise signaling. Until now, many stress-induced proteins including transcription factors (TFs), osmotic stress-adaptive proteins and key enzymes in abscisic acid (ABA) biosynthesis and signaling pathways have been reported [3-5].

The NAC [No apical meristem (NAM), Arabidopsis transcription activation factor (ATAF), and Cup-shaped cotyledon (CUC)] superfamily is one of the largest groups of plant-specific TFs, which not only play an important role in various stages of plant growth and development, but also participate in responses to biotic and abiotic stress [6-10]. Many NAC genes have been identified through their function in response to drought, cold, and high salinity stress [5]. Drought-induced genes ANAC019, ANAC055, and RD26/ANAC072, when overexpressed in Arabidopsis, improved 
drought tolerance [11,12]. Overexpression of SINAM1 from tomato could improve chilling tolerance of transgenic tobacco [13]. Besides, it has also been shown that OsNAC6 (from rice), SNAC2 (from rice), TaNAC4 (from wheat), TaNAC8 (from wheat), and CarNAC1 (from chickpea), function as transcriptional activators in response to various abiotic stresses [9,14-17].

The ATAF TFs comprise a sub-family of NAC proteins. The first report of a stress-inducible ATAF-like gene was StNAC from potato [18]. Elicited ATAF1 and ATAF2 are considered to function as repressors of responsive genes under biotic and abiotic stress, because ataf1 and ataf2 mutants showed high stress resistance [19-21]. However, overexpression of ATAF1 in Arabidopsis also exhibited enhanced plant tolerance to drought [22]. Subsequently, more ATAF family members from different species were explored in response to abiotic stress. OsNAC52 from rice belongs to the ATAF sub-family, and functions as an important transcriptional activator in ABA-inducible gene expression [23]. GmNAC2 plays a negative regulatory role in abiotic stress in Glycine max, and participates in the ROS signaling pathway by regulating the expression of ROS removal genes [24]. Overexpression of SINAC2 (from tomato) in Arabidopsis resulted in enhanced tolerance to salinity stress [25]. In addition, SINAC11 from tomato plays a stress-inducible TF role, depicting a positive response to abiotic stress tolerance [26]. $D g N A C 1$ from chrysanthemum worked as a positive regulator in responses to salt stress, as its overexpression in transgenic chrysanthemum showed lower levels of MDA (malondialdehyde) and reactive oxygen species $\left(\mathrm{H}_{2} \mathrm{O}_{2}\right.$ and $\left.\mathrm{O}^{2-}\right)$, greater activities of SOD (superoxide dismutase), POD (peroxidase) and CAT (catalase), as well as more proline content than wild-type (WT) under salt stress [27]. In addition, it was reported that CSATAF1 (from cucumber) was a crucial activator of the drought stress response via an ABA-dependent pathway, and inhibited ROS accumulation [28].

Strawberries are one of the most economically valuable crops in the world, which often suffers from water deficit, high salinity, flooding, and extreme temperature, leading to yield reduction [29-31]. Although many studies on responses of strawberry plants to abiotic stress have been reported, few data have showed NAC family members participating in abiotic stress resistance. Zhang et al. [31] showed that there are five FvNAC genes significantly contributing to various abiotic and biotic stress responses in woodland strawberry (Fragaria vesca), but their regulatory mechanisms are largely unknown.

In our study, FaNAC2 was isolated from the cultivar strawberry (Fragaria $\times$ ananassa, cultivar "Benihoppe"); it was highly expressed in shoot apical meristem and old leaves of strawberry plants, and showed especially high expression in the guard cells of leaves. FaNAC2 was induced under abiotic stress treatment, and many cis-acting elements that are responsive to abiotic stress were predicted in the FaNAC2 promoter. We overexpressed FaNAC2 in Nicotiana benthamiana (N. benthamiana), and found that the transgenic plants showed higher drought, cold and salt tolerance. These results indicated that FaNAC2 might play a positive role in plant responses to abiotic stress.

\section{Results}

\subsection{FaNAC2 Encodes an ATAF Protein that Belongs to the NAC Family}

FaNAC2 encodes a protein of 289 amino acids, and is a member of a plant-specific NAC family of transcription factors. We used the cDNA sequence of $F a N A C 2$ as a query to perform a BLAST search against 122 NAC family members of Arabidopsis, using MEGA 7.0 software. It was found that FaNAC2 has the closest relationship with AT1G01720, which encodes an ATAF sub-group protein, and is also named AtNAC2 (Figure 1A). A multiple sequence alignment of ATAF homologues from Arabidopsis, rose, Suaeda liaotungensis, soybean, cucumber and strawberry was performed. As shown in Figure 1B, high sequence similarities between FaNAC2 and other plant ATAF proteins were found in the N-terminus, which contained several distinguishable conserved domains, and five sub-domains. These results indicated that FaNAC2 encoded an ATAF1 protein and was a typical member of the NAC transcription factors. 
A

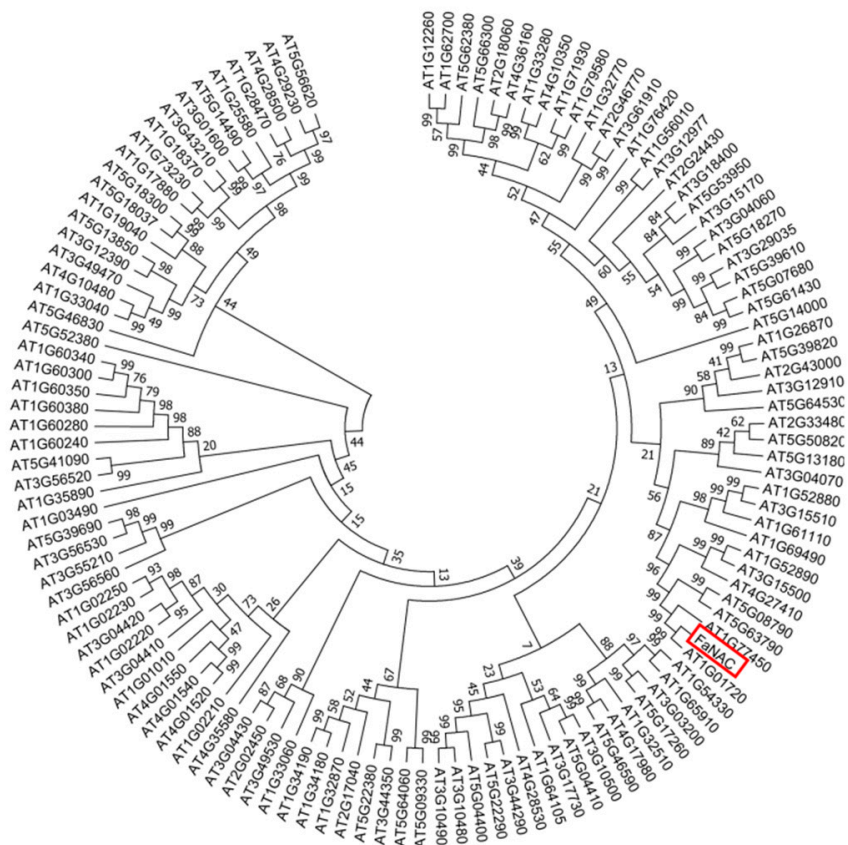

B

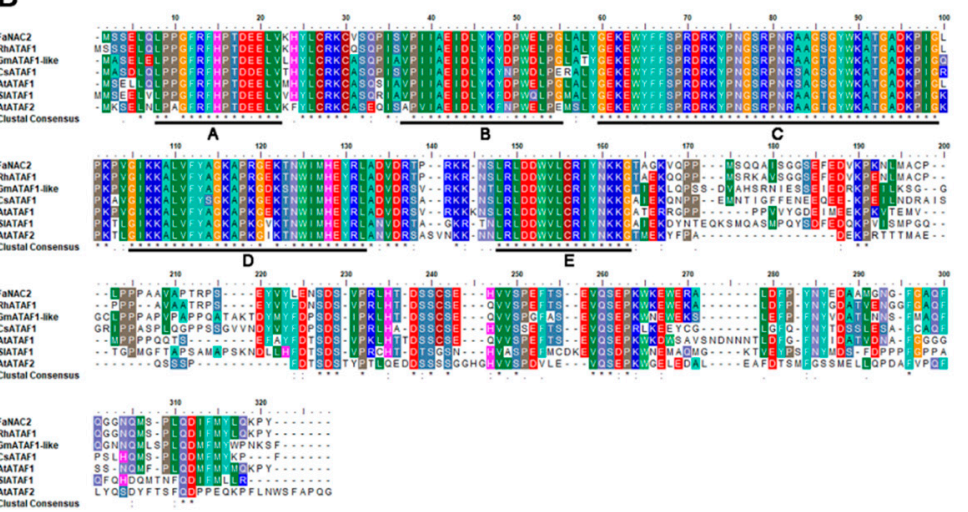

Figure 1. Phylogenetic analysis and amino acid sequence alignment of FaNAC2. (A) Phylogenetic relationship between FaNAC2 (red boxed) from strawberry and NAC family members in Arabidopsis. MEGA 7.0 software was used to construct the Neighbor-Joining tree. The nearest NAC gene is AT1G01720 (AtATAF1 or AtNAC2). (B) Protein sequence alignment of ATAFs. The black underlines indicate the conserved N-terminal domain of NAC family. A-E represent five conserved sub-domains. Accession Numbers: Rosa hybrid cultivar, RhATAF1 (AXT99858.1); Arabidopsis thaliana, AtATAF1 (AT1G01720), AtATAF2 (AT5G08790); Suaeda liaotungensis K., SINAC2 (JX860282.1); Glycine max, GmATAF1-like/GmNAC2 (AAX85979.1); Cucumis sativus L., CsATAF1 (Csa4M361820.1).

\subsection{Expression Pattern of FaNAC2}

To explore the function of $F a N A C 2$, we first analyzed its spatial and temporal expression patterns in strawberry plants. The qRT-PCR (quantitative RT-PCR) results showed that FaNAC2 was expressed at higher levels in shoot apical meristem, old leaves and flowers, compared to roots and fruits (Figure 2A). For different stages of leaves, the expression of FaNAC2 in older leaves was more than that in younger leaves and mature leaves, indicating that the accumulation of $F a N A C 2$ might increase with the senescence of leaves. Amongst the different sizes of flower buds, FaNAC2 had a high level of expression in the late petals and early stages of pistils (Figure 2A). 
A

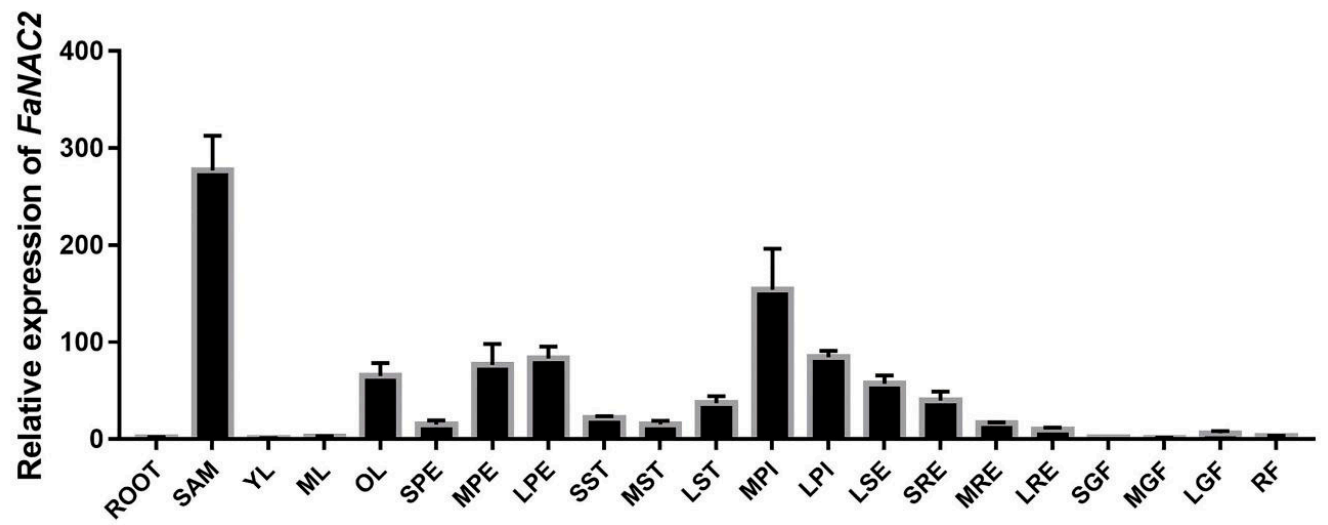

B

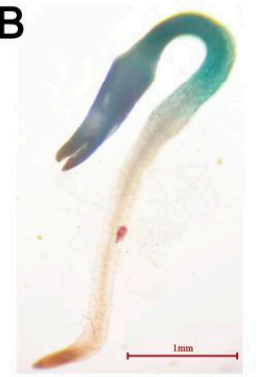

D

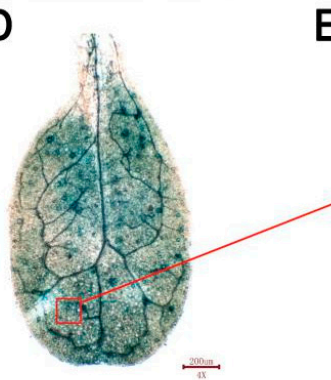

C

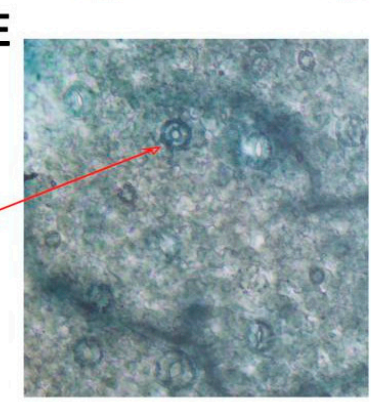

$\mathbf{F}$

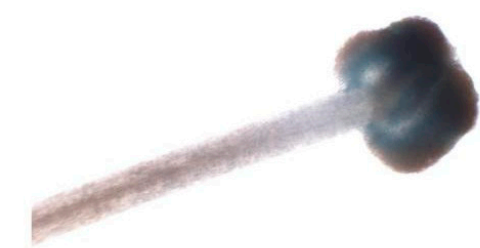

G

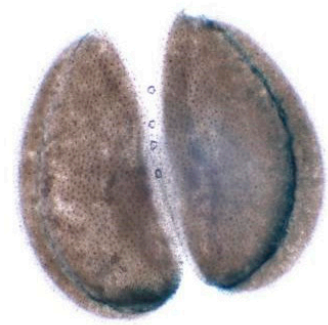

Figure 2. Expression pattern of FaNAC2. (A) qRT-PCR analysis of FaNAC2 in different tissues of strawberry. ROOT: roots; SAM: shoot apical meristem; YL: young leaves (the second folded leaf); ML: mature leaves (the third or fourth fully expanded leaf); OL: old leaves (below the seventh leaf); SPE: petals from small flower buds (length $<0.5 \mathrm{~cm}$ ); MPE: petals from middle flower buds (length 0.5-0.8 cm); LPE: petals from large opened flower; SST: stamen from small flower buds; MST: stamen from middle flower buds; LST: stamen from large opened flower; MPI: pistils from middle flower buds; LPI: pistils from large flower buds; LSE: sepals from large opened flower; SRE: receptacles from small flower buds; MRE: receptacles from middle flower buds; LRE: receptacles from large opened flower; SGF: small green fruits; MGF: middle green fruits; LGF: large green fruits; RF: red fruits. The FaACTIN gene was used as an internal reference to normalize the expression data. Data are presented as averages of three biological repeats. Bars are means $( \pm$ S.D.) of three independent experiments. (B,C) $\beta$-glucuronidase (GUS) analysis of 5 DAG (days after germination) ProFaNAC2-GUS $N$. benthamiana (Nicotiana benthamiana) seedlings. (D,E) GUS analysis of true leaf of 13 DAG seedling and its enlarged view. The red arrow points to guard cells in $(E) .(F, G)$ GUS analysis of stigma and anther of 35 DAG ProFaNAC2-GUS lines after planting on soil.

To better understand the expression pattern of $F a N A C 2$, the transgenic $N$. benthamiana contained a $\beta$-glucuronidase (GUS) reporter gene which, under the control of FaNAC2 promoter, was produced and detected. The results revealed that the GUS signals were detected in cotyledons and true leaves of young plants (Figure 2B,C), and it showed strong expression in the guard cells of true leaves 
(Figure 2D,E), suggesting that FaNAC2 might have a function in controlling stoma. In addition, GUS expression was also be seen in the stigmas and anthers of the flowers (Figure 2F,G).

\subsection{FaNAC2 Is Induced by Cold, Salinity, and Drought Treatment}

Since many cis-elements related to abiotic stress, such as ABRE (response to abscisic acid), LTR (response to cold) and MBS (response to drought), were found on the promoter sequence of FaNAC2 (Table 1), we hypothesized that FaNAC2 would also respond to abiotic stress. Thus, we performed stress treatments, including $200 \mathrm{mM} \mathrm{NaCl}, 20 \%$ polyethylene glycol (PEG) 6000, and $4{ }^{\circ} \mathrm{C}$, to detect the expression changes of FaNAC2 using $3 \mathrm{MAC}$ (months after cutting node bud from runners) tissue cultured seedlings of strawberry for qRT-PCR assay. The results revealed that its expression was strongly up-regulated in both SAM (shoot apical meristem) and leaves in response to abiotic stress (Figure 3A,B). During cold and salt treatment, the expression of FaNAC2 in the SAM was induced at $3 \mathrm{~h}$ and then gradually decreased compared to the initial expression levels, while the expression of $F a N A C 2$ from the leaves was a little slower, being induced only at $6 \mathrm{~h}$ following stress. Under the condition of simulated drought treatment, $F a N A C 2$ showed a great difference in expression pattern in different tissues; although FaNAC2 was induced at $9 \mathrm{~h}$, the expression of FaNAC2 in the SAM was gradually decreased from $12 \mathrm{~h}$ after induction, while $F a N A C 2$ expression in the leaves increased at all the times tested, which indicated that $F a N A C 2$ might participate in drought stress response, mainly in the leaves.

Table 1. Predicted cis-elements in the promoter of FaNAC2.

\begin{tabular}{cccc}
\hline Cis-elements & Sequence & Number & Character \\
\hline ABRE & ACGTG & $4(+)$ & Response to abscisic acid \\
ARE & AAACCA & $1(+)$ & Response to anaerobic process \\
Box-4 & ATTAAT & $1(+)$ & Response to light \\
CGTCA-motif & CGTCA & $3(+)$ & Response to Jasmonic Acid \\
G-box & CACGTG & $7(+)$ & Response to light reaction \\
GCN4-motif & TGAGTCA & $1(+)$ & Involved in endosperm expression \\
LTR & CCGAAA & $1(+)$ & Response to cold \\
MBS & CAACTG & $1(+)$ & Response to drought \\
RY-element & CATGCATG & $1(+)$ & Specific seeds' regulation \\
TCA-element & TCAGAAGAGG & $2(+)$ & Response to salicylic acid \\
TGA-element & AACGAC & $2(+)$ & Response to auxin \\
\hline
\end{tabular}

To confirm the expression pattern, different stress treatments were performed at 7 DAG (days after germination) of ProFaNAC2-GUS N. benthamiana, and the results showed that the GUS expression became stronger under cold, simulated drought and salt stress, indicating that FaNAC2 could be induced by different abiotic stresses (Figure 3C). Taking all these results together, it could be inferred that $F a N A C 2$ might function in different tissues to cope with different stress conditions.

\subsection{Overexpression of FaNAC2 Improves Stress Tolerance in Transgenic N. benthamiana}

To further investigate how $F a N A C 2$ plays roles in abiotic stress resistance, $F a N A C 2$ was ectopically transformed into $N$. benthamiana under the control of a CaMV (Cauliflower Mosaic Virus)-35S promoter, and ten positive lines were obtained through screening using kanamycin and RT-PCR analysis. By observing the growth potential of germination of 13 DAG 35S::FaNAC2 and wild-type lines under salt treatments, we found that $35 S:: F a N A C 2$ lines exhibited better growth under salt stress; for example, the leaf areas of transgenic plants were larger than WT following salt treatments (Figure 4A,B), indicating that overexpression of $F a N A C 2$ promoted the salt tolerance of plants. 
A

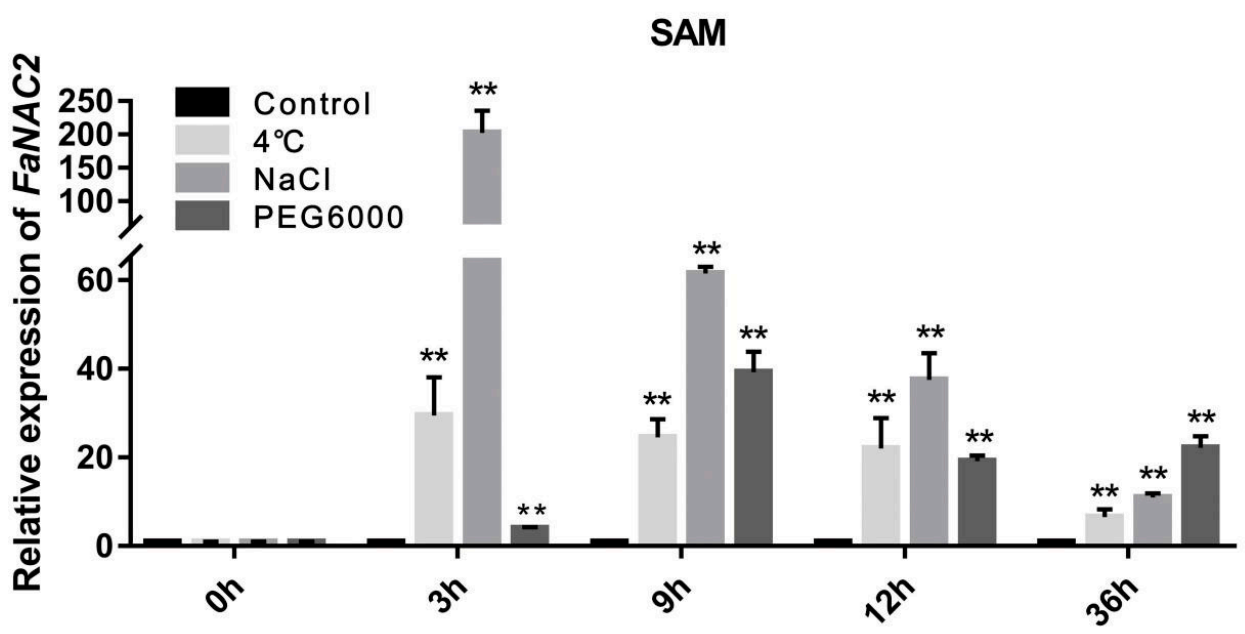

B

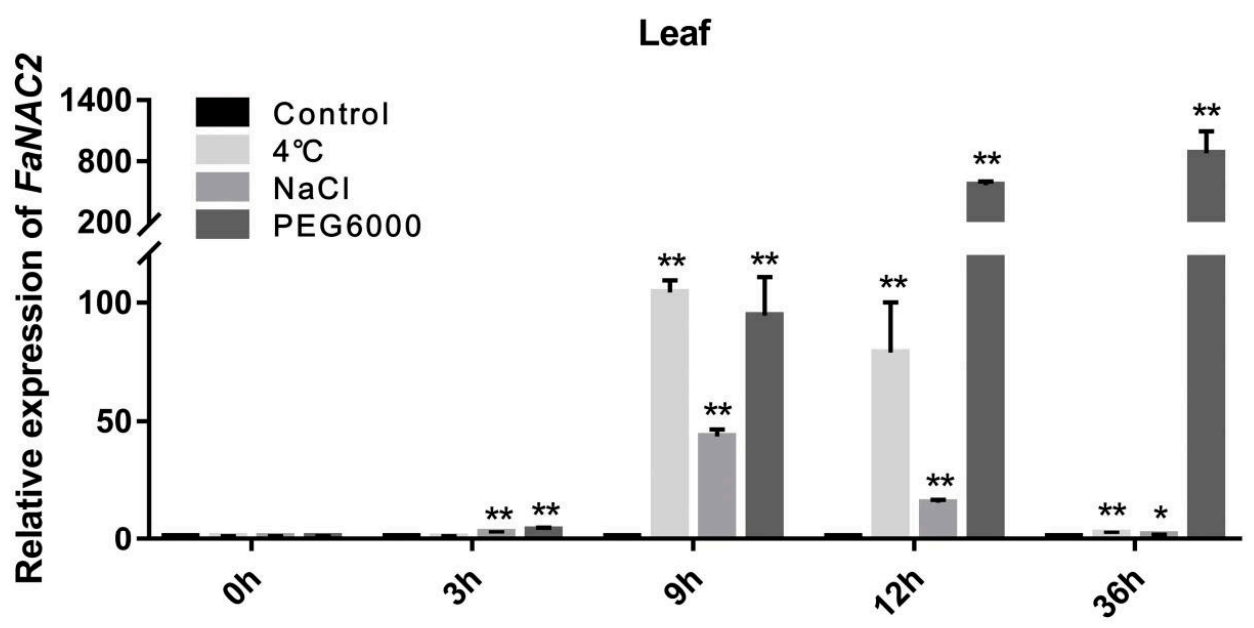

C

Time/h

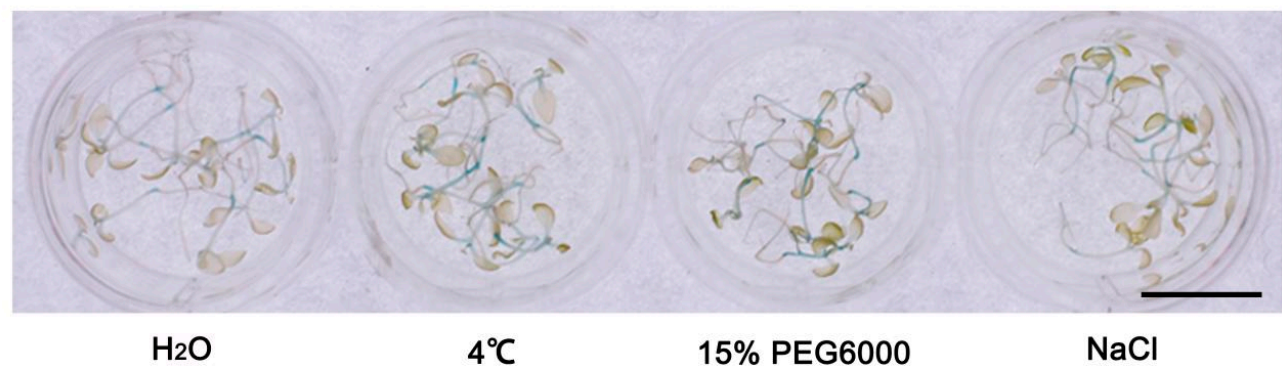

Figure 3. FaNAC2 is induced by cold, drought, and salinity stress. (A) The expression level of FaNAC2 in the SAM (shoot apical meristem) of strawberry under different abiotic stresses. (B) The expression level of FaNAC2 in the leaves of strawberry under different abiotic stresses. (C) Different abiotic stress treatments to 7 DAG (days after germination) ProFaNAC2-GUS seedlings. Salinity treatment used $200 \mathrm{mM} \mathrm{NaCl}$. Three independent experiments were performed and error bars indicate standard deviation (Student's $t$-test; ${ }^{*} p<0.05 ;{ }^{* *} p<0.01$ ). The scale bar represents $1 \mathrm{~cm}$. 

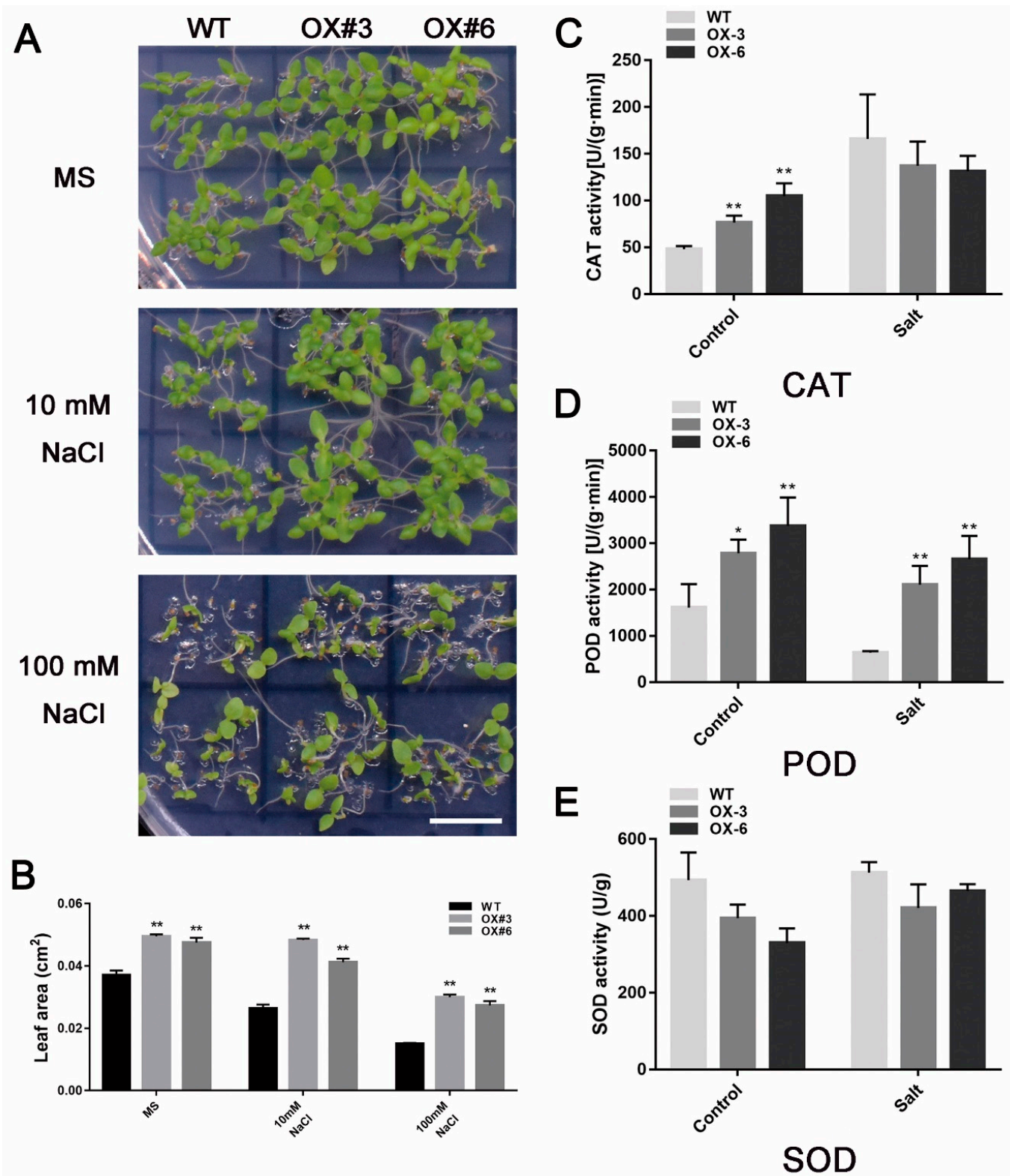

Figure 4. Comparison of resistance to salinity of 35S::FaNAC2 and wild-type (WT) lines. (A) Analysis of 13 DAG seedlings of 35S::FaNAC2 and WT seeds under salt and control treatments. OX: overexpression. (B) Leaf area of 35S::FaNAC2 and WT 13 DAG seedlings under salt and control treatments. (C-E) Enzyme activity of several enzymes related to plant resistance to salt. CAT: Catalase; POD: Peroxidase; SOD: Superoxide dismutase. The scale bar represents $1 \mathrm{~cm}$. Bars are means $( \pm$ S.D.) of three independent experiments (Student's $t$-test; ${ }^{*} p<0.05 ;{ }^{* *} p<0.01$ ).

As the plants get stronger, the 40 DAG 35S::FaNAC2 lines and WT plants were irrigated with $300 \mathrm{mM} \mathrm{NaCl}$ for one week, with normal watering as a control. By comparing the enzyme activity of antioxidant enzymes including catalase (CAT), peroxidase (POD) and superoxide dismutase (SOD) from two lines under different conditions, it was found that CAT enzyme activity in 35S::FaNAC2 lines was significantly higher than that in WT lines under control conditions, but there was no significant difference after salt treatment (Figure 4C). POD activity of 35S::FaNAC2 plants was higher than that of WT lines under both control and salt treatment, while there was no significant change in SOD enzyme activity (Figure $4 \mathrm{D}, \mathrm{E}$ ). These results suggested that $\mathrm{FaNAC2}$ might promote plant salt tolerance by partially affecting the activity of some antioxidant enzymes. 
Through different treatments for seed germination, we found that there was no difference in seed germination rates between 35S::FaNAC2 and WT lines under normal conditions. However, the seeds of 35S::FaNAC2 lines had a 10\% higher germination rates than that of WT plants under the treatment of simulated drought (10\% PEG 6000; Figure 5A,B). Subsequently, we conducted drought treatment on 40 DAG 35S::FaNAC2 and WT plants; 35S::FaNAC2 plants had a higher recovery rate after rehydration (Figure 5C). Comparing the WLR (water loss rate) from leaves of the two lines, it was found that the dryness of 35S::FaNAC2 leaves was lower, suggesting that they retained leaf water more easily (Figure 5D). Besides, a key gene for ABA biosynthesis, NbNCED1 (9-cis-epoxycarotenoid dioxygenase 1), was also detected in both the normal and drought treatment conditions, and NbNCED1 expression in 35S::FaNAC2 lines was significantly higher than that of WT (Figure 5E). Taking all these results together, our data suggested that FaNAC2 might exist as a positive regulator of drought stress tolerance.

A

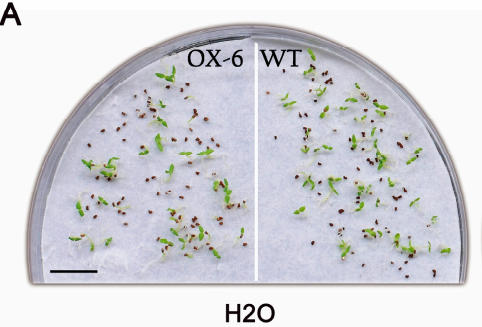
$\mathrm{H} 2 \mathrm{O}$

C

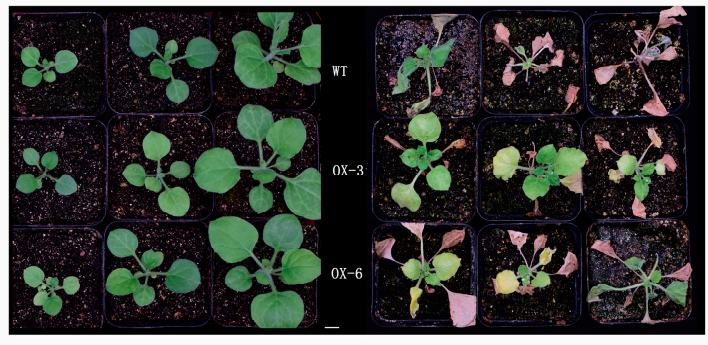

Control

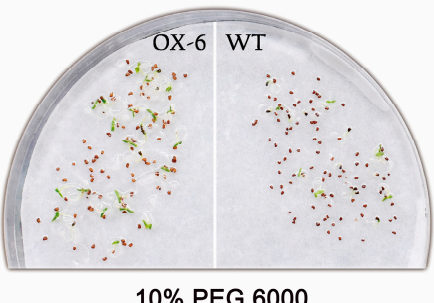

10\% PEG 6000
B

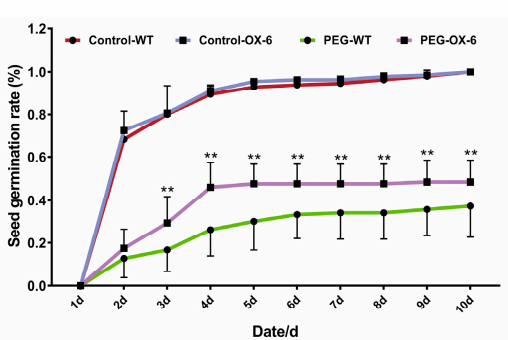

E

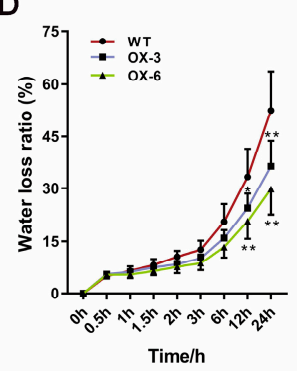

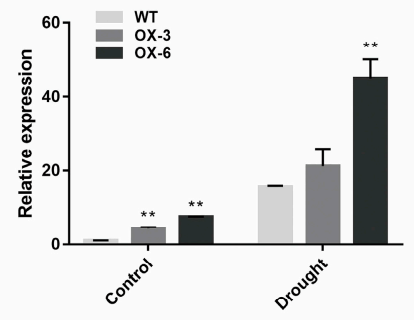

NbNCED1

Figure 5. Comparison the rehydration rate of 35S::FaNAC2 and WT lines under drought stress. (A,B) Germination rates of $35 \mathrm{~S}:: F a N A C 2$ and WT seeds under water and simulated drought conditions.

(C) Phenotypes of 40 DAG 35S::FaNAC2 and WT lines under control and rehydration conditions. (D) Water loss rate (WLR) of leaves from 35S::FaNAC2 and WT lines. (E) The qRT-PCR analysis of NbNCED1 expression, related to ABA biosynthesis pathways. The scale bar represents $1 \mathrm{~cm}$. Bars are means ( \pm S.D.) of three independent experiments (Student's $t$-test; ${ }^{*} p<0.05$; ${ }^{* *} p<0.01$ ).

In order to understand the function of FaNAC2 in cold stress, 35S::FaNAC2 lines and WT plants were subjected to cold treatment, which was performed as follows: $4{ }^{\circ} \mathrm{C}$ for $2 \mathrm{~h}, 0{ }^{\circ} \mathrm{C}$ for $1 \mathrm{~h},-5{ }^{\circ} \mathrm{C}$ for $1 \mathrm{~h}$ and $4^{\circ} \mathrm{C}$ for $1 \mathrm{~h}$. The results showed that 35S::FaNAC2 lines were more cold-resistant than WT plants, showing less damage (Figure 6A). Meanwhile, a key gene, NbNPK1 (Nicotiana protein kinase 1), which was involved in cold resistance signal transmission in plants, was found to show increased expression in 35S::FaNAC2 lines compared to WT plants under control treatment, while it was significantly higher than that in WT plants under cold treatment (Figure 6B). All of these results demonstrated that FaNAC2 might play a positive role in response to abiotic stress.

\subsection{FaNAC2 Promotes Plant Abiotic Stress Tolerance via Regulating Proline Metabolism}

To further investigate how FaNAC2 regulates plant stress tolerance, we detected the expression changes of key genes in proline biosynthesis, NbP5CS1 (Pyrroline-5 carboxylate synthetase 1), and catabolism, NbP5CDH (P5C dehydrogenase) and NbproDH2 (Proline dehydrogenase 2) from 35S::FaNAC2 and WT plants (Figure 7). Compared with WT, NbP5CS1 expression from 35S::FaNAC2 lines was increased either in control or salt stress conditions (Figure 7A,B). NbproDH2 expression 
was also higher in transgenic lines than WT in control conditions, while its expression significantly decreased after salt treatment. The expression of another key gene in the proline catabolism pathway, $\mathrm{NbP5CDH}$, in 35S::FaNAC2 lines was also down-regulated after salt treatment (Figure 7B).

A

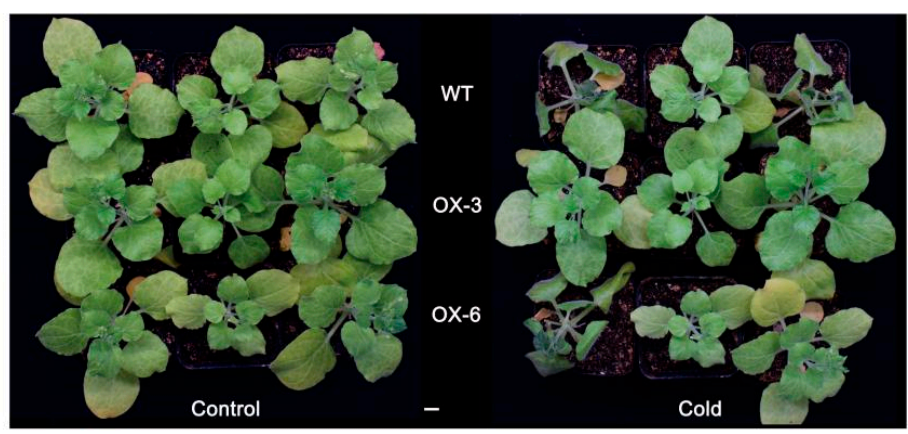

B

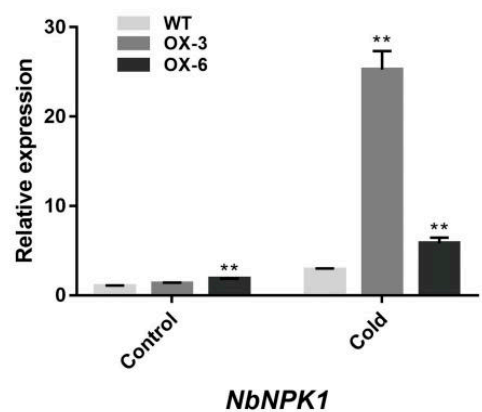

Figure 6. Comparison of 35S:::FaNAC2 and WT plants under cold stress. (A) Phenotypes of 35S::FaNAC2 lines and WT under control and cold conditions. (B) Expression of NbNPK1 related to plant resistance to cold pathways in 35S:::FaNAC2 lines and WT under cold treatment. The scale bar represents $1 \mathrm{~cm}$. Bars are means $\left( \pm\right.$ S.D.) of three independent experiments (Student's $t$-test; ${ }^{* *} p<0.01$ ).

A

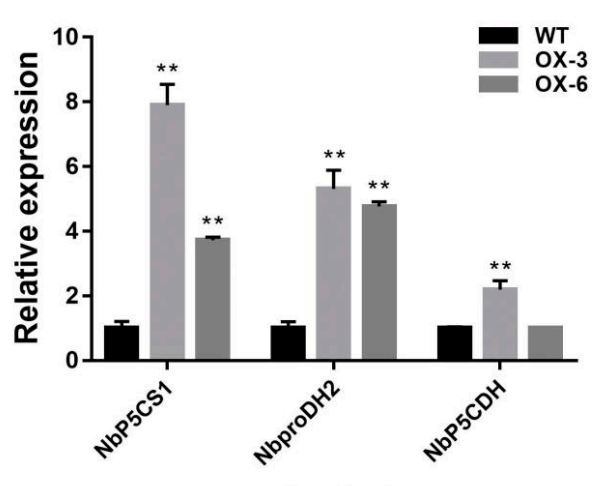

C

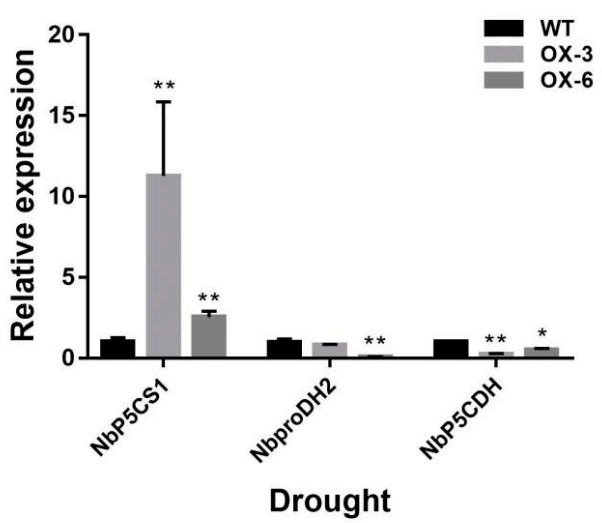

B

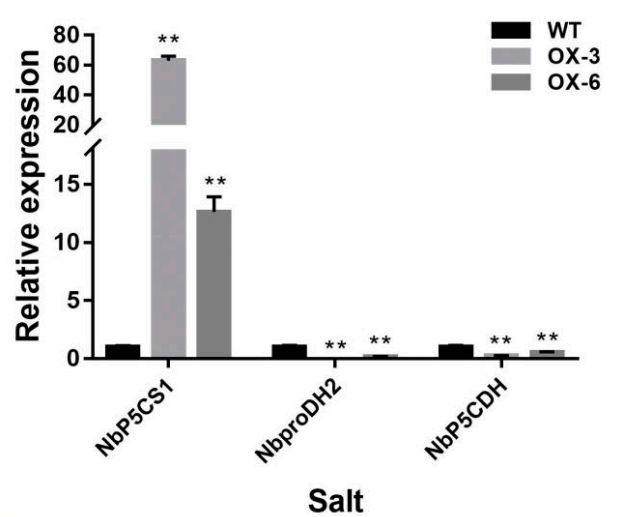

D

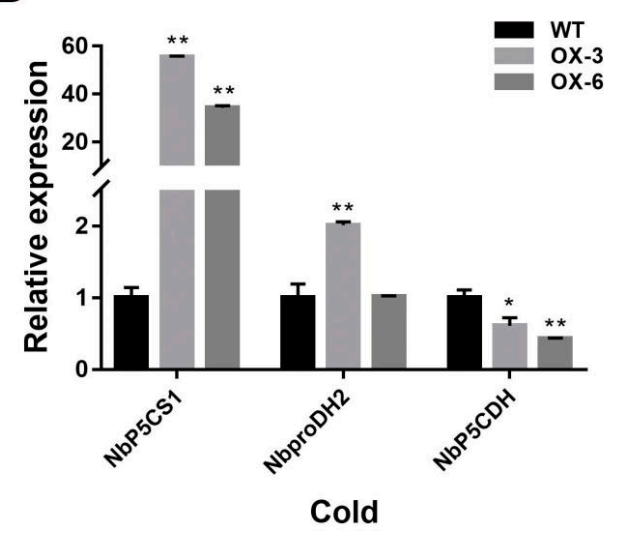

Figure 7. The qRT-PCR analysis of several genes related to proline matabolism in 35S::FaNAC2 lines and WT under different abiotic stress treatments. (A) Expression of genes in 35S::FaNAC2 lines and WT under control conditions. (B) Expression of genes in 35S::FaNAC2 lines and WT under salt stress. (C) Expression of genes in 35S::FaNAC2 lines and WT under drought stress. (D) Expression of genes in $35 \mathrm{~S}:: F a N A C 2$ lines and WT under cold stress. Bars are means ( \pm S.D.) of three biological replicantes experiments (Student's $t$-test; ${ }^{*} p<0.05 ;{ }^{* *} p<0.01$ ). 
Following drought treatment, the expression of NbP5CS1 in 35S::FaNAC2 was significantly higher than that of $\mathrm{WT}$, while the expression of $\mathrm{NbP} 5 \mathrm{CDH}$ and $\mathrm{NbproDH} 2$ was decreased compared with that of WT (Figure 7C).

Similar to the two previous stress treatments, further analysis revealed that the expression of NbP5CS1 was up-regulated in 35S::FaNAC2 lines under both control and cold treatment. The NbproDH2 expression of 35S::FaNAC2 lines was more than five times as high as that in WT plants under the control treatment, whereas it was twice as high as that in WT plants under the cold stress, suggesting that NbproDH2 of $35 \mathrm{~S}:: \mathrm{FaNAC} 2$ was decreased during the cold resistance compared to control condition. Meanwhile, $\mathrm{NbP5CDH}$ expression was relatively high in the control treatment, but lower in the WT plants after cold treatment (Figure 7D).

In addition, proline levels were detected under control and abiotic stress. It was found that proline content in 35S::FaNAC2 lines was slightly higher than WT plants in the control environment. With different abiotic stress treatments on the plants, proline content in 35S::FaNAC2 strains was significantly higher than WT strains (Figure 8). Due to both the proline biosynthesis gene and the proline catabolism gene being up-regulated under normal conditions, it was speculated that FaNAC2 might promote proline metabolism to sustain proline hemostasis for normal growth of transgenic plants, but $F a N A C 2$ could improve proline levels, in response to different abiotic stresses, for increased tolerance.

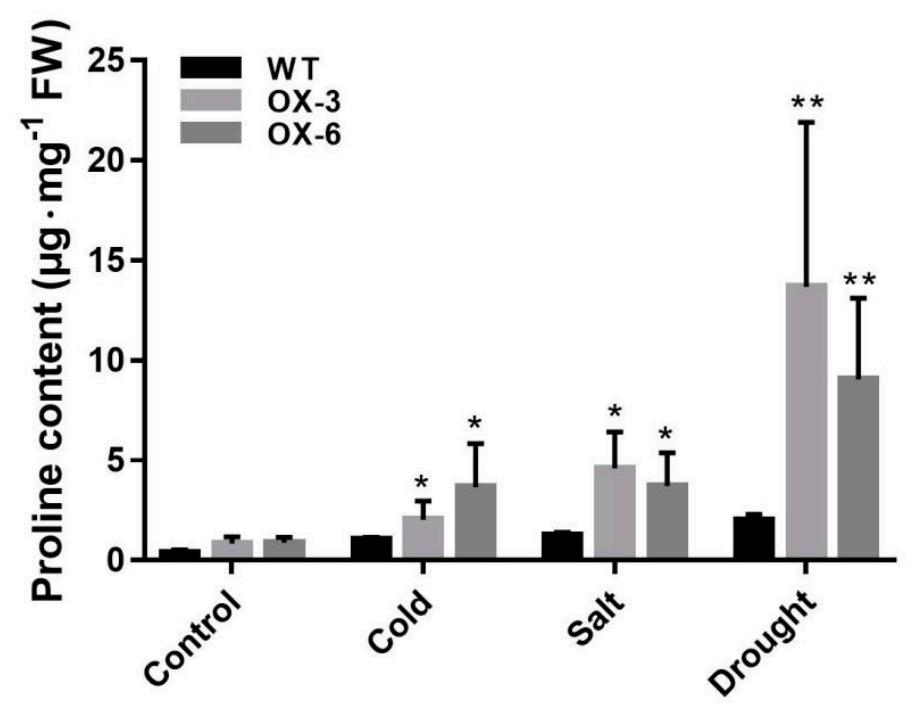

Figure 8. The proline content in 35S::FaNAC2 lines and WT leaves under different abiotic stress treatments. The fifth leaf was collected for proline content determination. Bars are means $( \pm$ S.D.) of three independent experiments (Student's $t$-test; ${ }^{*} p<0.05$; ${ }^{* *} p<0.01$ ).

Taking all of these results into account, we concluded that, in general, FaNAC2 might be involved in plant abiotic stress tolerance by regulating proline accumulation and catabolism.

\section{Discussion}

\subsection{The Expression Pattern of FaNAC2}

Many NAC family members have been reported to be involved in plant growth and development processes, such as SAM (shoot apical meristem) establishment, lateral root development, leaf senescence and cell wall formation [32-35]. Thus, we speculated that FaNAC2 may also be involved in many plant developmental processes. Our data show that $F a N A C 2$ might be involved in leaf senescence, as it expressed highly in old leaves (Figure 2A). These results are similar to the function of other members of the NAC family. Overexpression of OsNAC2 has been shown to promote leaf senescence via ABA biosynthesis [36], while ABA biosynthesis was also activated in the 35S::FaNAC2 N. benthamiana lines 
as our data shown (Figure 5), thus, whether FaNAC2 promotes leaf senescence via ABA synthesis needs further investigation.

GUS analysis showed high levels of $F a N A C 2$ promoter activity in guard cells of transgenic $N$. benthamiana leaves (Figure 2D,E). Considering these results, it is possible that there is a function for FaNAC2 in plant development. Stomata can affect transpiration and photosynthesis by regulating their closure with the changing environment, via sensing ABA signals under adverse conditions [37-40]. Thus, FaNAC2 may regulate transpiration and leaf water retention by adjusting guard cells. Besides, although the theory that root-sourced ABA can act as a signal to regulate stomatal aperture gained widespread acceptance, ABA biosynthetic mutants showed that stomatal aperture is predominantly regulated by leaf-sourced ABA [41-44]. In our results (Figure 5E), FaNAC2 could promote the key gene in ABA synthesis pathways in the leaf, thus we speculated that $F a N A C 2$ may regulate stomatal closure by participating in ABA biosynthesis in leaves, further improving the drought resistance of plants.

\subsection{FaNAC2 Functions as a Positive Regulator in Response to Abiotic Stress}

Abiotic stress is an important factor that threatens the yield and quality of strawberry. To alleviate the damage of abiotic stress, plants usually initiate complex adaptation via genetic mechanisms including regulation of gene expression and increased concentration of osmolytes [5,27]. There are several reports revealing that the ATAF sub-group of TFs belonging to the NAC family play important roles in response to abiotic stress; however, their function is still under debate. In Arabidopsis, ATAF1 was reported to negatively regulate stress-responsive gene expression during drought stress, because ataf1 mutants displayed higher recovery rates than WT under drought [20]. Overexpression of GmNAC2 reduces abiotic stress tolerance in Glycine max, which also functions as a negative regulator by participating in ROS signaling pathways [24]. It has been reported that AtATAF1 overexpression in transgenic lines enhanced drought tolerance [22]. Subsequently, OsNAC52 from rice, SINAC2 from tomato, $D g N A C 1$ from chrysanthemum and CsATAF1 from cucumber were reported to function as positive regulators in response to abiotic stress $[23,25,27,28]$.

In our study, GUS analysis showed that the promoter activity of strawberry FaNAC2 was induced by drought, salt and cold stress (Figure 3C), and FaNAC2 expression levels exhibited the same trend that was verified by qRT-PCR (Figure 3A,B) in strawberry. Besides, ectopic overexpression of FaNAC2 in N. benthamiana plants showed higher tolerance to salinity, drought and cold stress (Figures 4-6). Members of the ATAF sub-family in dicotyledons have conserved domains and can be identified by some conserved regions that respond positively to stress. Overexpressed transgenic lines of ANAC019, ANAC055 and ANAC072 improved the drought resistance of plants, and the conserved cis-elements CATGT and CACG, for their binding, were identified [12]. However, the central function of FaNAC2 in response to stress in strawberry is still unknown, and further studies on the abiotic stress pathway involving FaNAC2 are needed.

Proline accumulation has been reported to occur after biotic and abiotic stress [45-47]. It varies across different species under stress and can be more than 100 times higher than that under control conditions [48]. In our study, both the synthesis and catabolism pathways of proline were induced in $35 S:: F a N A C 2$ lines (Figure 7A), suggesting that the overexpression of $F a N A C 2$ can promote the metabolism of proline. However, in a stress environment, the expression levels of NbP5CS1 in 35S::FaNAC2 were still higher than that in $\mathrm{WT}$, and both $\mathrm{NbproDH} 2$ and $\mathrm{NbP5CDH}$ were decreased compared to control condition (Figure 7B-D). Further, the proline content of 35S::FaNAC2 was higher than WT under the abiotic stress condition (Figure 8). We speculate that FaNAC2 might promote the accumulation of proline under adverse conditions by activating proline synthesis and inhibiting proline degradation, so as to promote the stress tolerance of plants.

Taken together, $F a N A C 2$ from strawberry might play a positive role in response to abiotic stress by regulating proline metabolism. Although the role of $F a N A C 2$ in stress tolerance needs to be further validated in strawberries, we demonstrate that it can serve as a candidate gene to enhance stress tolerance, as long as the spatial-temporal expression is controlled. 


\section{Materials and Methods}

\subsection{Plant Materials, Growth Conditions}

The strawberry cultivar "Benihoppe" (Fragaria $\times$ ananassa Duch.) was used in this study and maintained in a plant culture room $\left(23 \pm 1^{\circ} \mathrm{C}\right.$, relative humidity of $40 \%, 16 \mathrm{~h} / 8 \mathrm{~h}$ light/dark cycles $)$. The tissue cultured seedlings were initiated from node bud of runners, which were collected from actively growing plants and disinfected with 70\% ethanol (30 s) and 1\% $\mathrm{NaClO}$ (10 min).

Most of N. benthamiana seeds were germinated on MS solid medium with $20 \%$ sucrose and grown for 13 days. Then, the seedlings were transplanted to the soil and grown in the culture room. For $N$. benthamiana seeds treated by simulate drought, the seeds were simply spread flat on a filter paper soaked in water or 10\% PEG 6000.

\subsection{Gene Isolation and Sequence Alignment}

Total RNA samples were extracted from collected shoot apicals and leaves using an E.Z.N.A Total RNA Kit (Omega., Norcross, Georgia, USA). HIScript II Reverse Transcriptase (Vazyme, Nanjing, China) was used for cDNA synthesis. The primers of FaNAC2 were designed according to the GDR Database (Genome Database for Rosaceae) [49]. The CDS (coding sequence) of FaNAC2 was obtained from the cDNA of "Benihoppe". Phylogenetic analysis was performed using MEGA version 7 (http://www.megasoftware.net/) [50]. Alignments of the FaNAC2 full-length amino acid sequence with ATAF homologues from other species were performed using BioEdit software (http: //www.mbio.ncsu.edu/BioEdit/bioedit.html) and ClustalW for multiple sequence alignments (http: //www.ch.embnet.org/software/ClustalW.html).

\subsection{Promoter Isolation, Prediction of Cis-Elements and GUS Activity Assay}

Genomic DNA was extracted from strawberry "Benihoppe" using a TIANquick Midi Purification Kit (TianGen., Beijing, China). The primers for the promoter of FaNAC2 were designed using the sequence from the GDR database and the sequence of the promoter was obtained using the DNA of "Benihoppe" strawberry as template, then the fragment was proofread and sequenced. FaNAC2 promoter was cloned into the pCAMBIA1391 vector using the TrelisfTM SoSoo cloning Kit (TsingKe, Beijing, China) to generate the reporter construct pCAMBIA1391-ProFaNAC2-GUS. The primers used are listed in Table S1. The construct was stably transformed into N. benthamiana by Agrobacterium-mediated transformation, as described below. Prediction of cis-elements was performed using the Plantcare online tool (http://bioinformatics.psb.ugent.be/webtools/plantcare/html/).

For GUS analysis, samples were incubated with GUS staining buffer (including $2 \mathrm{M}$ ferri/ ferrocyanide, $0.1 \%$ Triton $\mathrm{X}-100,0.1 \mathrm{M}$ sodium phosphate buffer, $0.5 \mathrm{mg} \cdot \mathrm{mL}^{-1} \mathrm{X}$-gluc, $\mathrm{pH} 7$ ) at $37^{\circ} \mathrm{C}$ for $9 \mathrm{~h}$, then stained samples were decolorized using $75 \%$ ethanol.

\subsection{Gene Expression Analysis}

qRT-PCR was employed to detect the expression of different genes. The qRT-PCR reactions $(20 \mu \mathrm{L}$ volume containing $500 \mathrm{ng}$ cDNA as template) were run using SYBR Premix ExTaq (TAKARA., Beijing, China) as enzyme and ABI QuantStudio ${ }^{\text {TM }} 6$ Flex PCR System (ABI., New York, NY, USA). The $2^{-\Delta \Delta C T}$ method was used for qRT-PCR analysis. FaACTIN and NbACTIN were used as internal controls for gene expression. The qRT-PCR primers of NbNCED1/NbNPK1/Nb5CS1/NbproDH2/NbP5CDH for qRT-PCR were designed according to the $N$. benthamiana database [51]. The template for analyzing the expression of these genes was cDNA of the fifth tobacco leaves from different treatments. PCR was performed in triplicate using RNA samples extracted from three independent plants. Each reaction was performed using three biological replicates and verified by melting curve analysis. The primers are listed in Table S1. 


\subsection{Stable Transformation of N. benthamiana}

For overexpression of FaNAC2 in N. benthamiana, the vector pCAMBIA2300 with kanamycin resistance was used for stable transformation. The FaNAC2 ORF was inserted into pCAMBIA2300 using the TrelisfTM SoSoo cloning Kit (TsingKe) and driven by a CaMV 35S promoter. The 35S::FaHAN was introduced into Agrobacterium tumefaciens strain GV3101 and then transformed into N. benthamiana leaf dishes by the method of Agrobacterium-mediated transformation [52]. The obtained kanamycin-resistant plants were screened again by RT-PCR. The PCR mix was from TsingKe and the PCR primers used for vector construction are listed in Table S1.

\subsection{Abiotic Stress Treatment}

The 3-months-old "Benihoppe" strawberry tissue cultured seedlings, which were obtained from the node bud of runners, were used for stress treatment. Three simulated stress conditions of $200 \mathrm{mM}$ $\mathrm{NaCl}, 20 \%$ PEG 6000 and $4{ }^{\circ} \mathrm{C}$ were set, and MS liquid medium was used as a control to treat for $0 \mathrm{~h}, 3 \mathrm{~h}$, $6 \mathrm{~h}, 12 \mathrm{~h}$ and $36 \mathrm{~h}$. The qRT-PCR was performed in biological triplicate using RNA samples extracted from three independent plants. For GUS staining, the abiotic stress treatment for 7 DAG (days after germination) N. benthamiana seedlings was $200 \mathrm{mM} \mathrm{NaCl}, 15 \%$ PEG 6000 and $4{ }^{\circ} \mathrm{C}$; the treatment lasted $12 \mathrm{~h}$.

Regarding abiotic stress treatment of 35S::FaNAC2 transgenic N. benthamiana lines and WT plants, simulated drought treatment for seeds was used with 10\% PEG 6000; drought treatment of 40 DAG seedlings was conducted by stopping the watering for $20 \mathrm{~d}$, until the leaves were all wilted, then re-watering for $5 \mathrm{~d}$ to observe the recovery of plants. Cold treatment was performed to put the plants under normal indoor conditions after $4{ }^{\circ} \mathrm{C}$ for $2 \mathrm{~h}, 0{ }^{\circ} \mathrm{C}$ for $1 \mathrm{~h},-5^{\circ} \mathrm{C}$ for $1 \mathrm{~h}$ and $4{ }^{\circ} \mathrm{C}$ for $1 \mathrm{~h}$, and the status of the plants was observed. Salt treatment for seedings of 35S::FaNAC2 and wild-type lines were MS solid medium with $10 \mathrm{mM} \mathrm{NaCl}$ and $100 \mathrm{mM} \mathrm{NaCl}$, respectively. Considering that $40 \mathrm{DAG}$ seedlings were stronger, salt treatment was enhanced to $300 \mathrm{mM} \mathrm{NaCl}$. These experiments were repeated three times and each line had three biological replicates.

\subsection{Determination of SOD, POD and CAT Enzyme Activities}

Approximately $0.15 \mathrm{~g}$ of the fifth expanded leaf from each line (including 35S::FaNAC2 and WT lines) was homogenized in $5 \mathrm{~mL}$ pre-cooled Phosphate buffered saline, at $4000 \mathrm{rpm}$ for $10 \mathrm{~min}$ at $4{ }^{\circ} \mathrm{C}$, then $2 \mathrm{~mL}$ of supernatant was drained and placed on ice for determination of different enzyme activities, according to measurements as follows.

CAT (Catalase) activity was measured spectrophotometrically at $240 \mathrm{~nm}$ [53]. The reaction mixture contained $100 \mathrm{mM}$ sodium phosphate buffer ( $\mathrm{pH} 7.0$ ), $30 \mathrm{mM} \mathrm{H}_{2} \mathrm{O}_{2}$ and $100 \mu \mathrm{L}$ of crude extract in a total volume of $3 \mathrm{~mL}$. The absorbance was read quickly every $1 \mathrm{~min}$, for a total of $4 \mathrm{~min}$.

The activity of POD (peroxidase) was determined at $420 \mathrm{~nm}$ using a spectrophotometer, with callus lignin as substrate. The reaction mixture contained $100 \mathrm{mM}$ sodium phosphate buffer (pH 6.0), $5 \mathrm{mM}$ hydrogen peroxide, $5 \mathrm{mM}$ guaiacol and $100 \mu \mathrm{L}$ crude extract, with a total volume of $3 \mathrm{~mL}$, at room temperature $\left( \pm 25^{\circ} \mathrm{C}\right)$ [54].

The activity of SOD (superoxide dismutase) was determined by inhibiting the photoreduction of SOD to NBT (nitro-blue tetrazolium) [55]. The reaction mixture contained a final volume of $3 \mathrm{~mL}$ of $50 \mathrm{mM}$ sodium phosphate buffer ( $\mathrm{pH}$ 7.6), $0.1 \mathrm{mM}$ Ethylene Diamine Tetraacetic Acid (EDTA)-Na , $50 \mathrm{mM}$ sodium carbonate, $12 \mathrm{mM}$ L-methionine, $50 \mathrm{mM}$ NBT, $10 \mu \mathrm{M}$ riboflavin and $100 \mu \mathrm{L}$ of crude extract. Then, the reaction mixture was exposed to white light for $30 \mathrm{~min}$ for the SOD reaction. After incubation, the absorbance was recorded at $560 \mathrm{~nm}$ with a spectrophotometer.

\subsection{Determination of WLR (Water Loss Rate) in N. benthamiana Leaves}

The fifth leaf was collected from half-month-old tobacco plants which were grown in the soil and dried naturally on filter paper. The temperature was $25^{\circ} \mathrm{C}$, the relative humidity was $38 \%$, and weight 
measurements were taken at $0 \mathrm{~h}, 0.5 \mathrm{~h}, 1 \mathrm{~h}, 1.5 \mathrm{~h}, 2 \mathrm{~h}, 3 \mathrm{~h}$, and $6 \mathrm{~h}$. This experiment was repeated three times to calculate the weight and rate of water loss in each period.

\subsection{Proline Measurement}

To determine free proline level, $0.1 \mathrm{~g}$ of fourth expanded leaf samples from each line (including 35S::FaNAC2 and WT lines) was homogenized in 3\% (w/v) sulphosalycylic acid and then homogenate filtered through filter paper [56]. The mixture was heated at $100{ }^{\circ} \mathrm{C}$ for $30 \mathrm{~min}$ in a water bath after the addition of acid ninhydrin and glacial acetic acid. The reaction was then stopped by ice bath. The mixture was extracted with toluene and the absorbance of the fraction with toluene aspired from the liquid phase was read at $520 \mathrm{~nm}$. Proline concentration was determined using a calibration curve.

\subsection{Statistical Analysis}

Microsoft Excel 2019 (Microsoft Corp., Redmond, Washington, USA) and GraphPad (GraphPad Software Inc., San Diego, California, USA) were used for analyzing the experimental data. Data for $p$-values were analyzed by Student's $t$ test at a significance level of 0.05 or 0.01 . Comparisons between multiple samples were determined using Tukey's multiple comparisons test.

Supplementary Materials: The following are available online at http://www.mdpi.com/2223-7747/9/11/1417/s1, Table S1: Primers used in this study.

Author Contributions: J.L. and J.Z. designed the experiments and performed the experiments; J.L., J.Z. and H.W. drafted the manuscript; J.L., H.W. and Z.W. revised the manuscript. All authors have read and agreed to the published version of the manuscript.

Funding: This work was supported by the National Key R\&D Program of China (2019YFD001800).

Acknowledgments: We thank Mingfang Yi (China Agricultural University, Beijing, China) for the generous gift of pCAMBIA2300 and pCAMBIA1391 vectors.

Conflicts of Interest: The authors declare no conflict of interest.

\section{References}

1. Choudhury, S.; Panda, P.; Sahoo, L.; Panda, S.K. Reactive oxygen species signaling in plants under abiotic stress. Plant Signal. Behav. 2013, 8, e23681. [CrossRef] [PubMed]

2. Choudhury, F.K.; Rivero, R.M.; Blumwald, E.; Mittler, R. Reactive oxygen species, abiotic stress and stress combination. Plant J. 2017, 90, 856-867. [CrossRef]

3. Zhu, J.K. Salt and drought stress signal transduction in plants. Ann. Rev. Plant Biol. 2002, 53, $247-273$. [CrossRef]

4. Zhu, J.K. Abiotic Stress Signaling and Responses in Plants. Cell 2016, 167, 313-324. [CrossRef] [PubMed]

5. Min, X.; Jin, X.; Zhang, Z.; Wei, X.; Ndayambaza, B.; Wang, Y.; Liu, W. Genome-Wide Identification of NAC Transcription Factor Family and Functional Analysis of the Abiotic Stress-Responsive Genes in Medicago sativa L. J. Plant Growth Regul. 2019, 1-14. [CrossRef]

6. Takada, S.; Hibara, K.; Ishida, T.; Tasaka, M. The CUP-SHAPED COTYLEDON1 gene of Arabidopsis regulates shoot apical meristem formation. Development 2001, 128, 1127-1135.

7. Mallory, A.C.; Dugas, D.V.; Bartel, D.P.; Bartel, B. MicroRNA Regulation of NAC-Domain Targets Is Required for Proper Formation and Separation of Adjacent Embryonic, Vegetative, and Floral Organs. Curr. Biol. 2004, 14, 1035-1046. [CrossRef]

8. Olsen, A.N.; Ernst, H.A.; Leggio, L.L.; Skriver, K. NAC transcription factors: Structurally distinct, functionally diverse. Trends Plant Sci. 2005, 10, 79-87. [CrossRef]

9. Nakashima, K.; Tran, L.S.P.; Van Nguyen, D.; Fujita, M.; Maruyama, K.; Todaka, D.; Ito, Y.; Hayashi, N.; Shinozaki, K.; Yamaguchi-Shinozaki, K. Functional analysis of a NAC-type transcription factor OsNAC6 involved in abiotic and biotic stress-responsive gene expression in rice. Plant J. 2007, 51, 617-630. [CrossRef]

10. Shao, H.; Wang, H.; Tang, X. NAC transcription factors in plant multiple abiotic stress responses: Progress and prospects. Front. Plant Sci. 2015, 6, 902. [CrossRef] 
11. Fujita, M.; Fujita, Y.; Maruyama, K.; Seki, M.; Hiratsu, K.; Ohme-Takagi, M.; Tran, L.P.; Yamaguchi-Shinozaki, K.; Shinozaki, K. A dehydration-induced NAC protein, RD26, is involved in a novel ABA-dependent stress-signaling pathway. Plant J. 2004, 39, 863-876. [CrossRef]

12. Tran, L.S.P.; Nakashima, K.; Sakuma, Y.; Simpson, S.D.; Fujita, Y.; Maruyama, K.; Fujita, M.; Seki, M.; Shinozaki, K.; Yamaguchi-Shinozaki, K. Isolation and functional analysis of Arabidopsis stress-inducible NAC transcription factors that bind to a drought-responsive cis-element in the early responsive to dehydration stress 1 promoter. Plant. Cell 2004, 16, 2481-2498. [CrossRef] [PubMed]

13. Li, X.D.; Zhuang, K.Y.; Liu, Z.M.; Yang, D.Y.; Ma, N.N.; Meng, Q.W. Overexpression of a novel NAC-type tomato transcription factor, SINAM1, enhances the chilling stress tolerance of transgenic tobacco. J. Plant. Physiol. 2016, 204, 54-65. [CrossRef] [PubMed]

14. Hu, H.; You, J.; Fang, Y.; Zhu, X.; Qi, Z.; Xiong, L. Characterization of transcription factor gene SNAC2 conferring cold and salt tolerance in rice. Plant. Mol. Biol. 2008, 67, 169-181. [CrossRef] [PubMed]

15. Peng, H.; Yu, X.; Cheng, H.; Shi, Q.; Zhang, H.; Li, J.; Ma, H. Cloning and characterization of a novel NAC family gene CarNAC1 from chickpea (Cicer arietinum L.). Mol. Biotechnol. 2010, 44, 30. [CrossRef]

16. Xia, N.; Zhang, G.; Liu, X.Y.; Deng, L.; Cai, G.L.; Zhang, Y.; Wang, X.J.; Zhao, J.; Huang, L.L.; Kang, Z.S. Characterization of a novel wheat NAC transcription factor gene involved in defense response against stripe rust pathogen infection and abiotic stresses. Mol. Biol. Rep. 2010, 37, 3703-3712. [CrossRef]

17. Xia, N.; Zhang, G.; Sun, Y.F.; Zhu, L.; Xu, L.S.; Chen, X.M.; Liu, B.; Yu, Y.T.; Wang, X.J.; Huang, L.L.; et al. TaNAC8, a novel NAC transcription factor gene in wheat, responds to stripe rust pathogen infection and abiotic stresses. Physiol. Mol. Plant. Pathol. 2010, 74, 394-402. [CrossRef]

18. Collinge, M.; Boller, T. Differential induction of two potato genes, Stprx2 and StNAC, in response to infection by Phytophthora infestans and to wounding. Plant. Mol. Biol. 2001, 46, 521-529. [CrossRef]

19. Delessert, C.; Kazan, K.; Wilson, I.W.; Straeten, D.V.D.; Manners, J.; Dennis, E.S.; Dolferus, R. The transcription factor ATAF2 represses the expression of pathogenesis-related genes in Arabidopsis. Plant. J. 2005, 43, 745-757. [CrossRef]

20. Lu, P.L.; Chen, N.Z.; An, R.; Su, Z.; Qi, B.S.; Ren, F.; Chen, J.; Wang, X.C. A novel drought-inducible gene, ATAF1, encodes a NAC family protein that negatively regulates the expression of stress-responsive genes in Arabidopsis. Plant. Mol. Biol. 2007, 63, 289-305. [CrossRef] [PubMed]

21. Mauch-Mani, B.; Flors, V. The ATAF1 transcription factor: At the convergence point of ABA-dependent plant defense against biotic and abiotic stresses. Cell Res. 2009, 19, 1322-1323. [CrossRef] [PubMed]

22. Wu, Y.; Deng, Z.; Lai, J.; Zhang, Y.; Yang, C.; Yin, B.; Zhao, Q.; Zhang, L.; Li, Y.; Yang, C.; et al. Dual function of Arabidopsis ATAF1 in abiotic and biotic stress responses. Cell Res. 2009, 19, 1279-1290. [CrossRef]

23. Gao, F.; Xiong, A.; Peng, R.; Jin, X.; Xu, J.; Zhu, B.; Chen, J.; Yao, Q. OsNAC52, a rice NAC transcription factor, potentially responds to $\mathrm{ABA}$ and confers drought tolerance in transgenic plants. Plant. Cell Tissue Organ. Cult. 2010, 100, 255-262. [CrossRef]

24. Jin, H.; Huang, F.; Cheng, H.; Song, H.; Yu, D. Overexpression of the GmNAC2 gene, an NAC transcription factor, reduces abiotic stress tolerance in tobacco. Plant. Mol. Biol. Rep. 2013, 31, 435-442. [CrossRef]

25. Yang, X.; Hu, Y.X.; Li, X.L.; Yu, X.D.; Li, Q.L. Molecular characterization and function analysis of SINAC2 in Suaeda liaotungensis K. Gene 2014, 543, 190-197. [CrossRef] [PubMed]

26. Wang, L.; Hu, Z.; Zhu, M.; Zhu, Z.; Hu, J.; Qanmber, G.; Chen, G. The abiotic stress-responsive NAC transcription factor SINAC11 is involved in drought and salt response in tomato (Solanum lycopersicum L.). Plant. Cell Tissue Organ. Culture 2017, 129, 161-174. [CrossRef]

27. Wang, K.; Zhong, M.; Wu, Y.; Bai, Z.; Liang, Q.; Liu, Q.; Pan, Y.; Zhang, L.; Jiang, B.; Jia, Y.; et al. Overexpression of a chrysanthemum transcription factor gene DgNAC1 improves the salinity tolerance in chrysanthemum. Plant. Cell Rep. 2017, 36, 571-581. [CrossRef]

28. Wang, J.; Zhang, L.; Cao, Y.; Qi, C.; Li, S.; Liu, L.; Wang, G.; Mao, A.; Ren, S.; Guo, Y. CsATAF1 positively regulates drought stress tolerance by an ABA-dependent pathway and by promoting ROS scavenging in cucumber. Plant. Cell Physiol. 2018, 59, 930-945. [CrossRef]

29. Brown, J.; Voth, V. Salt damage to strawberries: Types of water, irrigation system, and soil condition found to influence salt accumulation in strawberry plantings. Calif. Agric. 1955, 9, 11-12.

30. Razavi, F.; Pollet, B.; Steppe, K.; Van, L.M.C. Chlorophyll fluorescence as a tool for evaluation of drought stress in strawberry. Photosynthetica 2008, 46, 631-633. [CrossRef] 
31. Zhang, H.; Kang, H.; Su, C.; Qi, Y.; Liu, X.; Pu, J. Genome-wide identification and expression profile analysis of the NAC transcription factor family during abiotic and biotic stress in woodland strawberry. PLoS ONE 2018, 13, e0197892. [CrossRef] [PubMed]

32. Souer, E.; van Houwelingen, A.; Kloos, D.; Mol, J.; Koes, R. The no apical meristem gene of Petunia is required for pattern formation in embryos and flowers and is expressed at meristem and primordia boundaries. Cell 1996, 85, 159-170. [CrossRef]

33. He, X.J.; Mu, R.L.; Cao, W.H.; Zhang, Z.G.; Zhang, J.S.; Chen, S.Y. AtNAC2, a transcription factor downstream of ethylene and auxin signaling pathways, is involved in salt stress response and lateral root development. Plant. J. 2005, 44, 903-916. [CrossRef] [PubMed]

34. Mitsuda, N.; Seki, M.; Shinozaki, K.; Ohme-Takagi, M. The NAC transcription factors NST1 and NST2 of Arabidopsis regulate secondary wall thickenings and are required for anther dehiscence. Plant. Cell 2005, 17, 2993-3006. [CrossRef]

35. Uauy, C.; Distelfeld, A.; Fahima, T.; Blechl, A.; Dubcovsky, J. A NAC gene regulating senescence improves grain protein, zinc, and iron content in wheat. Science 2006, 314, 1298-1301. [CrossRef]

36. Mao, C.; Lu, S.; Lv, B.; Zhang, B.; Shen, J.; He, J.; Luo, L.; Xi, D.; Chen, X.; Ming, F. A rice NAC transcription factor promotes leaf senescence via ABA biosynthesis. Plant. Physiol. 2017, 174, 1747-1763. [CrossRef]

37. Hetherington, A.M.; Woodward, F.I. The role of stomata in sensing and driving environmental change. Nature 2003, 424, 901-908. [CrossRef] [PubMed]

38. Roelfsema, M.R.G.; Levchenko, V.; Hedrich, R. ABA depolarizes guard cells in intact plants, through a transient activation of R-and S-type anion channels. Plant. J. 2004, 37, 578-588. [CrossRef]

39. Zhang, Y.; Xu, W.; Li zhong Deng, X.; Wu, W.; Xue, Y. F-Box Protein DOR Functions as a Novel Inhibitory Factor for Abscisic Acid-Induced Stomatal Closure under Drought Stress in Arabidopsis. Plant. Physiol. 2008, 148, 4. [CrossRef]

40. Lawson, T.; Blatt, M.R. Stomatal size, speed, and responsiveness impact on photosynthesis and water use efficiency. Plant. Physiol. 2014, 164, 1556-1570. [CrossRef]

41. Holbrook, N.M.; Shashidhar, V.R.; James, R.A.; Munns, R. Stomatal control in tomato with ABA-deficient roots: Response of grafted plants to soil drying. J. Exp. Bot. 2002, 53, 1503-1514. [PubMed]

42. Christmann, A.; Weiler, E.W.; Steudle, E.; Grill, E. A hydraulic signal in root-to-shoot signalling of water shortage. Plant. J. 2007, 52, 167-174. [CrossRef] [PubMed]

43. Mc Adam, S.A.; Sussmilch, F.C.; Brodribb, T.J. Stomatal responses to vapour pressure deficit are regulated by high speed gene expression in angiosperms. Plant. Cell Environ. 2016, 39, 485-491. [CrossRef]

44. Zhang, F.; Sussmilch, F.; Nichols, D.S.; Cardoso, A.A.; Brodribb, T.J.; McAdam, S.A.M. Leaves, not roots or floral tissue, are the main site of rapid, external pressure-induced ABA biosynthesis in angiosperms. J. Exp. Bot. 2018, 69, 5. [CrossRef] [PubMed]

45. Saradhi, P.P.; AliaArora, S.; Prasad, K. Proline accumulates in plants exposed to UV radiation and protects them against UV-induced peroxidation. Biochem. Biophys. Res. Commun. 1995, 209, 1-5. [CrossRef]

46. Hare, P.D.; Cress, W.A. Metabolic implications of stress-induced proline accumulation in plants. Plant. Growth Regul. 1997, 21, 79-102. [CrossRef]

47. Siripornadulsil, S.; Traina, S.; Verma, D.P.S.; Sayre, R.T. Molecular mechanisms of proline-mediated tolerance to toxic heavy metals in transgenic microalgae. Plant. Cell 2002, 14, 2837-2847. [CrossRef]

48. Verbruggen, N.; Hermans, C. Proline accumulation in plants: A review. Amino acids 2008, 35, 753-759. [CrossRef]

49. Jung, S.; Ficklin, S.P.; Lee, T.; Cheng, C.H.; Blenda, A.; Zheng, P.; Yu, J.; Bombarely, A.; Cho, I.; Ru, S.; et al. The Genome Database for Rosaceae (GDR): Year 10 update. Nucleic Acids Res. 2014, 42, D1237-D1244. [CrossRef]

50. Kumar, S.; Stecher, G.; Tamura, K. MEGA7: Molecular evolutionary genetics analysis version 7.0 for bigger datasets. Mol. Biol. Evol. 2016, 33, 1870-1874. [CrossRef]

51. Fernandez-Pozo, N.; Menda, N.; Edwards, J.D.; Saha, S.; Tecle, I.Y.; Strickler, S.R.; Bombarely, A.; Fisher-York, T.; Pujar, A.; Foerster, H.; et al. The Sol Genomics Network (SGN)—From genotype to phenotype to breeding. Nucleic Acids Res. 2015, 43, D1036-D1041. [CrossRef] [PubMed]

52. Wydro, M.; Kozubek, E.; Lehmann, P. Optimization of transient Agrobacterium-mediated gene expression system in leaves of Nicotiana benthamiana. Acta Biochim. Pol. 2006, 53, 289-298. [CrossRef] [PubMed] 
53. Bergmeyer, H.U.; Graßl, M. Methods of Enzymatic Analysis, 3rd ed.; Verlag Chemie: Weinheim, Germany, 1983; pp. 267-268.

54. Onsa, G.H.; bin Saari, N.; Selamat, J.; Bakar, J. Purification and characterization of membrane-bound peroxidases from Metroxylon sagu. Food Chem. 2004, 85, 365-376. [CrossRef]

55. Oktay, M.; Küfreviolu, I.; Kocaçalişkan, I.; Şaklrolu, H. Polyphenoloxidase from Amasya apple. J. Food Sci. 1995, 60, 494-496. [CrossRef]

56. Bates, L.S.; Waldren, R.P.; Teare, I.D. Rapid determination of free proline for water-stress studies. Plant. Soil 1973, 39, 205-207. [CrossRef]

Publisher's Note: MDPI stays neutral with regard to jurisdictional claims in published maps and institutional affiliations.

(C) 2020 by the authors. Licensee MDPI, Basel, Switzerland. This article is an open access article distributed under the terms and conditions of the Creative Commons Attribution (CC BY) license (http://creativecommons.org/licenses/by/4.0/). 